\title{
Subjective Well-Being in Nostalgia: Effect and Mechanism
}

\author{
Min Rao, Xiaotian Wang, Hailong Sun, Kun Gai \\ School of Management, Jinan University, Guangzhou, China \\ Email:c7ronaldo@foxmail.com
}

How to cite this paper: Rao, M., Wang, X. T., Sun, H. L., \& Gai, K. (2018). Subjective Well-Being in Nostalgia: Effect and Mechanism. Psychology, 9, 1720-1730. https://doi.org/10.4236/psych.2018.97102

Received: July 1, 2018

Accepted: July 9, 2018

Published: July 12, 2018

Copyright (C) 2018 by authors and Scientific Research Publishing Inc. This work is licensed under the Creative Commons Attribution International License (CC BY 4.0).

http://creativecommons.org/licenses/by/4.0/

\begin{abstract}
Nostalgia is a complex emotional state that the individual produces when he is missing the past. It has a close relationship with subjective well-being. Studies have shown that nostalgia can construct a sense of life and social support that promotes more emotional and emotional satisfaction and enhances subjective well-being. By combing the past literature, this paper analyzes the influence of nostalgia on subjective well-being from the perspectives of emotional happiness and life satisfaction, and further elaborates its mechanism of action. The article concludes with a prospect for future research.
\end{abstract}

\section{Keywords}

Nostalgia, Emotional Happiness, Subjective Well-Being, Life Satisfaction, Meaning in Life, Social Support

\section{Introduction}

In psychology research, nostalgia is a complex emotional state that individuals experience when they think about the past. It is a ubiquitous emotional experience (Sedikides, Wildschut, \& Baden, 2004; Sedikides, Wildschut, Arndt, \& Routledge, 2006; Barrett, Grimm, Robins, Wildschut, Sedikides, \& Janata, 2010). Nostalgia has many important physiological and psychological effects: increase creativity, relieve pain, increase positive emotions, ease negative emotions, increase self-esteem and sense of life, increase social support, etc. (van Tilburg, Sedikides, \& Wildschut, 2015; Zhou, Wildschut, Sedikides, Chen, \& Vingerhoets, 2012; Bryant, Smart, \& King, 2005; Wildschut, Sedikides, Arndt, \& Routledge, 2006). The emotional experience is an important component of subjective well-being (Diener, 1984), an increase in self-esteem and sense of life (Baumeister, Campbell, Krueger, \& Vohs, 2003) and an increase in social support 
(Chu, Saucier, \& Hafner, 2010) can improve subjective well-being. It can be seen that nostalgia is inextricably linked to subjective well-being (Routledge, Wildschut, Sedikides, \& Juhl, 2013). Defining the influence of nostalgia on subjective well-being and its mechanism of action is conducive to society, enterprises and individuals to improve their subjective well-being and create a good social atmosphere through nostalgic methods. Therefore, in order to provide theoretical support for improving the subjective well-being of individuals, and provide guidance for practice. This article will explain the impact and the psychological mechanisms behind the nostalgia and subjective well-being by combing through the past literature.

\section{The Influence of Nostalgia on Subjective Well-Being}

\subsection{The Influence of Nostalgia on Emotional Happiness}

Emotional experience is an important component of emotional well-being in subjective well-being. It can be divided into positive and negative emotions. Emotional happiness is the balance between these two emotional experiences. Positive emotions increase people's sense of well-being and negative emotions decrease. Human happiness. In simple terms, emotional well-being is the difference between positive and negative emotions that people experience. Higher emotional happiness is composed of more positive emotions and lower negative emotions (Keyes, 2013).

There is a close relationship between nostalgia and positive emotions. The research of Wildschut et al. (2006) found that the content narrative of nostalgic stories contains more positive factors. Compared with those who recalled their daily experiences in the past, those who recalled their nostalgic experiences reported more positive emotions, and their perceptions of the past were more positive, and they included more positives in narratives of nostalgia. Sexual factors. This shows that nostalgia is a store of positive emotions. It can store the positive emotions experienced by individuals in previous experiences in a timely manner and provide them with resources for positive emotions in future memories. In the study of Hepper et al. (2012), participants were asked to list words that could accurately represent nostalgic characteristics. The words associated with positive emotions (consolation/warmth, calm/relaxation) appeared most frequently. Similarly, if the participants in the nostalgic group and the control group were allowed to write a nostalgic event or an ordinary event in life during the experiment, all subjects were then asked to complete the emotion test scale, and the content analysis method was used to test the events written by the participants after the experiment. The analysis showed that the contents of the nostalgic events written by the participants were mostly positive. Compared with the control group participants, the nostalgic group participants had a higher level of positive emotions. The above studies show that nostalgia can promote the development of positive emotions, increase people's positive emotions, and increase emotional happiness. A recent study successfully inspired the nostalgic 
feelings of the participants through specific topical websites (such as asking participants to read short messages sent by others to those who had ever loved ones; watching the images of individuals holding past photos). It was found that nostalgia promoted the positive emotions of the participants (Cox, Kersten, Routledge, Brown, \& Van Enkevort, 2015).

In addition, Wildschut et al. (2006) explored the relationship between nostalgia and negative emotions, suggesting that nostalgia does not alleviate negative emotions. In the study, they were randomly divided into nostalgic group and control group. The nostalgic group was nostalgic by letting the participants imagine nostalgic situations and recalling nostalgic events; the control group described ordinary events that occurred in the previous week, and then let all be Try to score on the emotional scale, the results show that the scores of positive emotions of the nostalgic group and the control group were significantly different, but the negative emotion score, although the nostalgic group was slightly lower than the control group, but did not reach a significant level, so they think Nostalgia can only play a role in enhancing positive emotions and does not have the effect of alleviating negative emotions. In the study of Cox et al. (2015), it was found that compared with the participants in the control group, the nostalgia inspired by other people's situation was not significantly different in the negative emotional dimensions measured by the PANAS scale, indicating that nostalgia does not relieve negative emotions. However, Wildschut, Sedikides, \& Cordaro (2011) found that nostalgic means such as encouraging older people to talk about what happened in the past, watching old photos and collecting commemorative items, listening to old songs, etc., can promote more conversations between the elderly and the intervenors, effectively preventing Or reduce depression, also increase overall subjective well-being. So nostalgia can ease negative emotions? What causes the difference in results? It is worth noting that the state of nostalgia is used in the above studies, and Juhl, Routledge, Arndt, Sedikides, \& Wildscht (2010) explore the relationship between nostalgic tendencies (stale nostalgia) and death anxiety. Among them, the Southampton Nostalgia Scale (SNS) was used to measure the nostalgic tendencies of the subjects, and the scores were divided into high nostalgia tendency group and low nostalgia tendency group according to the score level, and then they were randomly assigned to the experimental group (death highlight group, "A brief description of what your emotions are when you think about your own death?") and the control group (Pain highlights the group, "Short description, when you think of your own severe pain, how is your mood?") Finally measure their anxiety about death. The results showed that under the low nostalgic tendency, the death anxiety in the experimental group was significantly higher than that in the control group; under the high nostalgic tendency, there was no significant difference in the death anxiety level between the experimental group and the control group, indicating that the high nostalgia level can reduce the anxiety caused by death. Nostalgia has the effect of relieving anxiety. At the same time, studies in recent years have found that for those who are habitually anxious, nostalgia can not only re- 
lieve anxiety, but also increase anxiety (Verplanken, 2012).

Why does nostalgia have such different effects on negative emotions? We believe that the nature of nostalgia itself, especially the difference between state nostalgia and nostalgia, may play an important role in it. Previous studies are often more induced by state nostalgia. Research on nostalgia for traits is not deep enough, nostalgia for state and nostalgia for special qualities. The difference between the two needs further discussion. In addition, there are still many inconsistencies in the nostalgia of different natures for specific negative emotions, such as anxiety and depression. It is necessary to pay special attention to the negative emotions measured in studies that have concerns for old negative emotions, including depression, Anxiety specific negative emotions, but also the overall negative emotions, the results of the difference is due to the measurement of different content? On the other hand, more studies have focused on the elderly population. Older people have their unique psychological characteristics, but negative emotions such as depression and anxiety also exist in other age groups. In the future, different age groups can be further strengthened. The group's nostalgic influence on depression, anxiety, and other negative emotions should distinguish between negative and specific negative emotions.

\subsection{The Influence of Nostalgia on Life Satisfaction}

Studies have found that nostalgia plays an important role in improving the life satisfaction of older people. Wildschut et al. (2011) found that the elderly's nostalgia was started by watching old photos and souvenirs and listening to old songs. At the same time, negative emotions also improve the life satisfaction of the elderly, which in turn improves the overall subjective well-being. At the same time, Gao, Feng, Yuan, \& He (2011) explored the influence of psychological interventions of nostalgic groups on depression symptoms and life satisfaction of elderly people in the community, and used the GDS screen for elderly people in the community. Ninety-six community elderly patients with mild to moderate depressive symptoms were randomly divided into intervention and control groups according to their community. The control group received regular community health education. The intervention group performed a 6-week nostalgic group psychological intervention. The GDS score and life satisfaction index A scale were compared between the two groups before the start of the intervention and at the end of the 6-week intervention. (LSIA) score. The results showed that the score of GDS in the intervention group after psychological intervention was lower than that before the intervention and the control group, and the LSIA score was higher than that before the intervention and the control group. This shows that the psychological intervention of the nostalgic group helps to alleviate the depressive symptoms of the elderly in the community and improve their life satisfaction.

Why nostalgia can improve the elderly's life satisfaction, and then increase the subjective well-being? Butler's life review theory believes that human development exists in all stages of life. The memories of past events in old age (ie, nos- 
talgia) can be seen as an important asset in life, which makes individuals more widely available. The growth of meaning achieves the effect of improving life satisfaction (Cook, 1998; Webster, Bohlmeijer, \& Westerhof, 2010). However, studies have found that nostalgia can not only improve the life satisfaction of the elderly, but also have an important role for other adults. The study of Cox et al. (2015) stimulated nostalgic subjects to score significantly more in life satisfaction than the control group. This means that nostalgia provides individual life satisfaction. The theory of life review explains well the reasons why nostalgia raises the life satisfaction of older people, but how does one explain the influence of nostalgia on individual life satisfaction in other age groups? Does nostalgic content (such as positive or negative) or nostalgic nature (nostalgic nostalgia and state nostalgia) have different effects on individual's life satisfaction? We believe that the impact of nostalgia on life satisfaction is not only related to the content of nostalgia itself, but also closely related to the individual's assessment of nostalgic content. When nostalgia focuses on reliance on past experiences, and can confidently face the current life, Nostalgia is related to the improvement of life satisfaction. If this is indeed the case, further exploration is needed.

In summary, it can be found that nostalgia has an important influence on the positive components of subjective well-being of individuals, negative emotions, and life satisfaction. Existing research shows that nostalgia promotes the improvement of individual positive emotions. Hepper et al. (2012) explained the nostalgic psychology using Prototypical Conceptions. Hepper et al. believe that nostalgic prototypes include central features (such as happiness, longing, thoughts, etc.) and marginal features (regret, sadness, pain, etc.), and that the more central features included in a person's nostalgic concept, nostalgia are The greater the positive effect. The results of a recent cross-cultural study also show that more than 1000 participants from 18 different cultures use the same way of thinking about nostalgia, and they show high consistency when ranking 35 nostalgic features. Individuals in all countries are more likely to rank central features as nostalgic prototypes compared to marginal features (Hepper et al., 2014). But whether or not nostalgia can effectively relieve negative emotions and why it can improve life satisfaction has not been well explained. So, what is the mechanism of nostalgia for subjective well-being?

\section{The Mechanism of Nostalgia Affecting Subjective Well-Being}

The self-conscious emotions proposed by Tracy and Robins (2004) can explain the mechanism of nostalgia's subjective well-being to a certain extent. The so-called self-consciousness emotion depends on the emotional experience induced by self-consciousness and social environment. In addition to the basic emotions of anger and sadness, human beings also have emotions such as pride, guilt, and shame. The development and effects of these emotions have certain differences for different groups of people. Self-consciousness can regulate social behavior. At the same time, nostalgia is generally considered as a kind of emo- 
tional connection with the self (Vess, Arndt, Routledge, Sedikides, \& Wildschut, 2012; Batcho, 2013; Routledge et al., 2013). behavior. Self-consciousness emotions mainly involve two important dimensions of self and social relations (Hepper et al., 2014). Therefore, we believe that: the impact of nostalgia on subjective well-being mainly through two aspects, one is the self-related factors, such as the meaning of life. The other is social relations, such as social support.

\subsection{Nostalgic Construct the Meaning in Life}

Human beings are creatures that need meaningful construction. Studies have shown that people will take multiple paths to make their lives meaningful (Sedikides et al., 2004). The meaning of life is usually considered to be the most basic psychological resource to cope with the actual anxiety and stress. It is a symbol of high quality of life. It is an important symbol of healthy mental function that senses that life is full of meaning (Updegraff, Cohen Silver, \& Holman, 2008). In general, people with a high sense of life can better cope with stressful events in life. They have a higher subjective well-being than people with a low sense of life (Park, 2010). Studies have shown that the purpose of life and the meaning of life can influence well-being at all stages of life (from juvenile to old age) (Zika \& Chamberlain, 1992).

Nostalgia, as a desire to return to the past, is a resource for perceiving and maintaining a sense of life (Juhl et al., 2010; Routledge, Arndt, Sedikides, \& Wildschut, 2008; Routledge et al., 2011). Since nostalgic memories involve the precious life experience between subjects and other intimate individuals, nostalgia may promote the perception of life meaning through this important experience (Routledge, Wildschut, Sedikides, \& Juhl, 2013). Routledge et al. (2011) evoked nostalgia through the lyrics and asked participants to write three lyrics that could evoke their nostalgia. The result was that there was a significant correlation between high-level nostalgia and a high level of sense of life, which successfully triggered nostalgia for the participants. After the emotions (presenting nostalgic lyrics or memories of nostalgia), the nostalgic group scored significantly higher on the Prescence of Meaning in Life subscale than the control group (presenting ordinary lyrics or imagining the future). Subjects. At the same time, when people perceive that their own lives have a higher sense of meaning, they will reduce the pursuit of meaning. This also shows that nostalgia can make people perceive a higher sense of life and reduce the pursuit of meaning of life. When the meaning of life feels a threat, people also tend to use more nostalgia to ease the decline of sense of meaning. Based on this, Routledge, Wildschut, Sedikides, Juhl, \& Arndt (2012) further showed that they were compared Thinking about recent positive experiences or expected future experiences, nostalgia will give participants a stronger sense of meaning. Nostalgic memories may be an important source of meaning for people's lives. From the above studies, it can be seen that individuals with a high sense of life tend to think that their own lives are more meaningful and have a higher degree of satisfaction with their own lives. This is the impact on subjective well-being. Nostalgia is a source of life 
meaning, and this sense of life can bring people a higher happiness experience. Therefore, the effect of nostalgia on subjective well-being can be achieved through the enhancement of sense of life.

\subsection{Nostalgia Enhances Social Support}

Influencing subjective well-being by enhancing social support is another way of nostalgia for subjective well-being. Social support refers to all forms of help that a person feels from family members, friends, neighbors, and others, including objectively visible practical support (material direct assistance and social networks, the existence and participation of group relations), and Subjective experience of emotional support (individuals are respected in society, supported, understood emotional experience and satisfaction). Social support is an important external resource that can be used by individuals. It can provide people with material or information help, increase people's sense of joy and belonging, improve people's self-esteem and self-confidence, and when people face stressful life events. At the same time, it can also prevent or alleviate the stress response, thereby increasing positive emotions and suppressing the generation of negative emotions and preventing the decrease of subjective well-being (Barrera, Sandler, \& Ramsay, 1981). Social support is an important influencing factor of subjective well-being. It is positively related to positive emotions. Individuals can obtain a higher sense of well-being only if they receive various social supports (Mogilner, 2010; Chu et al., 2010). Different aspects of social support also have different effects on subjective well-being: actual support obtained and expectations for support can predict life satisfaction, embedding family and providing support can predict positive emotions, and expecting support can predict negative emotions (Siedlecki, Salthouse, Oishi, \& Jeswani, 2014). Individuals with good social support generally have higher subjective well-being, life satisfaction, positive emotions, and lower negative emotions (Meehan, Durlak, \& Bryan, 1993).

Nostalgia, as a complex emotional experience, is also a strategy for enhancing social support (Hart, Sedikides, Wildschut, Arndt, Routledge, \& Vingerhoets, 2011). Nostalgia usually occurs in a social context in which individuals place themselves in and recall those important people and the important things that happen with them. In this process, individuals can regain important relationships, increase their connections with society, feel more love and protection from society, and gain a sense of belonging, feeling that they are not isolated in this society. Instead, it is in a wide range of strong social support (Wildschut et al., 2006; Wildschut, Sedikides, Routledge, \& Arndt, 2010). Social support is an important factor affecting subjective well-being. Higher social support can place individuals in a wide range of social connections. It plays a crucial role in improving individuals' positive emotions and life satisfaction, as well as reducing negative emotions. The important role of nostalgia is to have a positive effect on subjective well-being through this enhanced effect on social support.

Existing research shows that nostalgia can have a positive impact on subjective well-being through ways such as improving self-esteem, constructing a sense of 
life, and enhancing social support. According to the self-conscious emotions proposed by Tracy and Robins (2004), we think that nostalgia is also a selfexperiment that is closely related to self, affecting subjective well-being through two major aspects of self and social relations. Different dimensions. If nostalgia promotes subjective well-being through the meaning of life, self-esteem, and social support, then in addition to this, whether other self and social relationships play a role, such as gratitude as a positive personality trait or life orientation also exists universally, thanksgiving in nostalgia What is the role of subjective well-being?

\section{Research Prospects}

At present, a separate study of nostalgia and subjective well-being has yielded rich results. It is generally believed that nostalgia is a universal and complex emotional experience. Subjective well-being is a subjective measure of the quality of individual life that includes emotional and cognitive components index. Although studies have shown that nostalgia has a direct or indirect impact on subjective well-being (Cox, Kersten, Routledge, Brown, \& Van Enkevort, 2015), how does nostalgia affect subjective well-being, emotional well-being and life satisfaction? What is the psychological mechanism that nostalgia affects subjective well-being? At present, no clear conclusion has been drawn. The next phase of nostalgic research on subjective well-being can also be explored in the following areas:

1) Nostalgia influences subjective well-being through other paths of self and social relationships. In addition to the above-mentioned factors such as selfesteem, meaning of life, and social support that play an important role in the impact of nostalgia on subjective well-being, whether or not gratitude plays an important role in the impact of nostalgia on subjective well-being has not yet been clearly addressed. Gratitude is an individual's positive personality traits or life orientation. Studies have shown that gratitude has a wide range of adaptive functions, and in particular it can uniquely predict individual well-being (Emmons \& McCullough, 2003; Froh, Yurkewicz, \& Kashdan, 2009; Wood, Joseph, \& Maltby, 2009). Individuals who are grateful are happy. Compared with individuals who are not grateful, they experience more positive emotions (satisfaction, happiness, hope) and less negative emotions (jealousy, depression, etc.), and they control the Big Five personality and social appreciating effects. Afterwards, thanksgiving still has a significant predictive effect, indicating that gratitude has a unique effect on these indicators (Watkins, Woodward, Stone, \& Kolts, 2003). It can be seen that gratitude is positively correlated with subjective well-being, which also provides a strong theoretical basis for nostalgia to improve subjective well-being through gratitude, but at present, there is no experimental data support, and future research can further explore gratitude in nostalgia. Subjective well-being affects the mediating role.

2) Pay attention to nostalgic application research. From previous studies, it 
can be seen that the existing nostalgia treatment is mainly targeted at the elderly (especially those with senile dementia and elderly patients with depression). Through the nostalgic intervention to achieve the effect of relieving depression, it will improve life satisfaction and subjective well-being. However, a large number of studies have shown that nostalgia is an emotional experience that prevails in all populations. At the same time, nostalgia also has an important role in increasing social support and improving the sense of life. Can this be depression (mainly characterized by a sense of nonessential life)? Does the treatment help? Does the nostalgic effect of relieving anxiety provide advice for the treatment of anxiety? In this rapidly developing and stress-increasing society, depression and anxiety disorders have become high-prevalence diseases among the young and middle-aged groups. Through the study of the treatment of depression and anxiety disorders in nostalgia, it is an effective way for the improvement of the well-being experience of various groups of people.

\section{Fund}

This article is funded by the Humanities and Social Sciences Research Project of the Ministry of Education of China. Item number: 15YJA630051.

\section{References}

Barrera, M., Sandler, I. N., \& Ramsay, T. B. (1981). Preliminary Development of a Scale of Social Support: Studies on College Students. American Journal of Community Psychology, 9, 435-447. https://doi.org/10.1007/BF00918174

Barrett, F. S., Grimm, K. J., Robins, R. W., Wildschut, T., Sedikides, C., \& Janata, P. (2010). Music-Evoked Nostalgia: Affect, Memory, and Personality. Emotion, 10, 390-403. https://doi.org/10.1037/a0019006

Bryant, F., Smart, C. M., \& King, S. P. (2005). Using the Past to Enhance the Present: Boosting Happiness through Positive Reminiscence. Journal of Happiness Studies, 6, 227-260. https://doi.org/10.1007/s10902-005-3889-4

Chu, P. S., Saucier, D. A., \& Hafner, E. (2010). Meta-Analysis of the Relationships between Social Support and Well-Being in Children and Adolescents. Journal of Social and Clinical Psychology, 29, 624-645. https://doi.org/10.1521/jscp.2010.29.6.624

Cook, E. (1998). Effects of Reminiscence on Life Satisfaction of Elderly Female Nursing Home Residents. Health Care for Women International, 19, 109-118. https://doi.org/10.1080/073993398246449

Diener, E. (1984). Subjective Well-Being. Psychological Bulletin, 95, 542-575. https://doi.org/10.1037/0033-2909.95.3.542

Emmons, R. A., \& McCullough, M. E. (2003). Counting Blessings versus Burdens: An Experimental Investigation of Gratitude and Subjective Well-Being in Daily Life. Journal of Personality and Social Psychology, 84, 377-389. https://doi.org/10.1037/0022-3514.84.2.377

Froh, J. J., Yurkewicz, C., \& Kashdan, T. B. (2009). Gratitude and Subjective Well-Being in Early Adolescence: Examining Gender Differences. Journal of Adolescence, 32, 633-650. https://doi.org/10.1016/j.adolescence.2008.06.006

Gao, J., Feng, H., Yuan, Q., \& He, G. P. (2011). Effects of Psychological Interventions of Nostalgic Groups on Depression Symptoms and Life Satisfaction of the Elderly in the 
Community. Chinese Journal of Gerontology, 31, 386-388.

Hart, C. M., Sedikides, C., Wildschut, T., Arndt, J., Routledge, J., \& Vingerhoets, A. J. M. (2011). Nostalgic Recollections of High and Low Narcissists. Journal of Research in Personality, 45, 238-242. https://doi.org/10.1016/j.jrp.2011.01.002

Hepper, E. G., Ritchie, T. D., Sedikides, C., \& Wildschut, T. (2012). Odyssey’s End: Lay Conceptions of Nostalgia Reflect Its Original Homeric Meaning. Emotion, 12, 102-119. https://doi.org/10.1037/a0025167

Hepper, E. G., Wildschut, T., Sedikides, C., Ritchie, T. D., Yung, Y.-F., Zhou, X. Y. et al. (2014). Pancultural Nostalgia: Prototypical Conceptions across Cultures. Emotion, 14, 733-747. https://doi.org/10.1037/a0036790

Juhl, J., Routledge, C., Arndt, J., Sedikides, C., \& Wildschut, T. (2010). Fighting the Future with the Past: Nostalgia Buffers Existential Threat. Journal of Research in Personality, 44, 309-314. https://doi.org/10.1016/j.jrp.2010.02.006

Keyes, C. L. M. (2013). Promoting and Protecting Positive Mental Health: Early and Often throughout the Lifespan. In C. L. M. Keyes (Ed.), Mental Well-Being International Contributions to the Study of Positive Mental Heallth (pp. 3-28). Berlin: Springer. https://doi.org/10.1007/978-94-007-5195-8_1

Meehan, M. P., Durlak, J. A., \& Bryant, F. B. (1993). The Relationship of Social Support to Perceived Control and Subjective Mental Health in Adolescents. Journal of Community Psychology, 21, 49-55. https://doi.org/10.1002/1520-6629(199301)21:1<49::AID-JCOP2290210106>3.0.CO;2-I

Mogilner, C. (2010). The Pursuit of Happiness: Time, Money, and Social Connection. Psychological Science, 21, 1348-1354. https://doi.org/10.1177/0956797610380696

Park, C. M. (2010). Making Sense of the Meaning Literature: An Integrative Review of Meaning Making and Its Effects on Adjustment to Stressful Life Events. Psychological Association, 136, 257-301. https://doi.org/10.1037/a0018301

Routledge, C., Arndt, J., Sedikides, C., \& Wildschut, T. (2008). A Blast from the Past: The Terror Management Function of Nostalgia. Journal of Experimental Social Psychology, 44, 132-140. https://doi.org/10.1016/j.jesp.2006.11.001

Routledge, C., Arndt, J., Wildschut, T., Sedikides, C., Hart, C., Juhl, J., Vingerhoets, A. J., \& Scholtz, W. (2011). The Past Makes the Present Meaningful: Nostalgia as an Existential Resource. Journal of Personality and Social Psychology, 101, 638-652. https://doi.org/10.1037/a0024292

Routledge, C., Wildschut, T., Sedikides, C., Juhl, J., \& Arndt, J. (2012). The Power of the Past: Nostalgia as a Meaning-Making Resource. Memory, 20, 452-460. https://doi.org/10.1080/09658211.2012.677452

Routledge, C., Wildschut, T., Sedikides, C., \& Juhl, J. (2013). Nostalgia as a Resource for Psychological Health and Well-Being. Social and Personality Psychology Compass, 7, 808-818. https://doi.org/10.1111/spc3.12070

Sedikides, C., Wildschut, T., \& Baden, D. (2004). Nostalgia: Conceptual Issues and Existential Functions. In J. Greenberg, S. Koole, \& T. Pyszczynski (Eds.), Handbook of EXperimental Existential Psychology (pp. 200-214). New York, NY: Guilford.

Sedikides, C., Wildschut, T., Arndt, J., \& Routledge, C. (2006). Self and Affect: The Case of Nostalgia. In J. P. Forgas (Ed.), Affect in Social Thinking and Behavior: Frontiers in Social Psychology (pp. 197-215). New York, NY: Psychology Press.

Siedlecki, K. L., Salthouse, T. A., Oishi, S., \& Jeswani, S. (2014). The Relationship between Social Support and Subjective Well-Being across Age. Social Indicators Research, 117, 561-576. https://doi.org/10.1007/s11205-013-0361-4 
Updegraff, J. A., Cohen Silver, R., \& Holman, E. A. (2008). Searching for and Finding Meaning in Collective Trauma: Results from a National Longitudinal Study of the 9/11 Terrorist Attacks. Journal of Personality and Social Psychology, 95, 709-722. https://doi.org/10.1037/0022-3514.95.3.709

van Tilburg, W. A. P., Sedikides, C., \& Wildschut, T. (2015). The Mnemonic Muse: Nostalgia Fosters Creativity through Openness to Experience. Journal of Experimental Social Psychology, 59, 1-7.

Vess, M., Arndt, J., Routledge, C., Sedikides, C., \& Wildschut, T. (2012). Nostalgia as a Resource for the Self. Self and Identity, 3, 273-284. https://doi.org/10.1080/15298868.2010.521452

Watkins, P. C., Woodward, K., Stone, T., \& Kolts, R. L. (2003). Gratitude and Happiness: Development of a Measure of Gratitude, and Relationships with Subjective Well-Being. Social Behavior and Personality, 31, 431-452. https://doi.org/10.2224/sbp.2003.31.5.431

Webster, J. D., Bohlmeijer, E. T., \& Westerhof, G. Y. (2010). Mapping the Future of Reminiscence: A Conceptual Guide for Research and Practice. Research on Aging, 32, 527-564. https://doi.org/10.1177/0164027510364122

Wildschut, T., Sedikides, C., \& Cordaro, F. (2011). Self-Regulatory Interplay between Negative and Positive Emotions: The Case of Loneliness and Nostalgia. In Emotion Regulation and Well-Being (pp. 67-83). New York, NY: Springer. https://doi.org/10.1007/978-1-4419-6953-8_5

Wildschut, T., Sedikides, C., Arndt, J., \& Routledge, C. D. (2006). Nostalgia: Content Triggers, Functions. Journal of Personality and Social Psychology, 91, 975-993. https://doi.org/10.1037/0022-3514.91.5.975

Wildschut, T., Sedikides, C., Routledge, C., \& Arndt, J. (2010). Nostalgia as a Repository of Connectedness: The Role of Attachment-Related Avoidance. Journal Personality and Social Psychology, 98, 573-586. https://doi.org/10.1037/a0017597

Wood, A. M., Joseph, S., \& Maltby, J. (2009). Gratitude Predicts Psychological Well-Being above the Big Five Facets. Personality and Individual Differences, 46, 443-447. https://doi.org/10.1016/j.paid.2008.11.012

Zhou, X. Y., Wildschut, T., Sedikides, C., Chen, X., \& Vingerhoets, J. J. M. (2012). Heartwarming Memories: Nostalgia Maintains Physiological Comfort. Emotion, 12, 678-684. https://doi.org/10.1037/a0027236 